\title{
Association between hyperleptinemia and cardiovascular outcomes in patients with coronary artery disease
}

This article was published in the following Dove Press journal:

Therapeutics and Clinical Risk Management

\author{
Ming-Chun Chen ${ }^{1, *}$ \\ Ji-Hung Wang ${ }^{2,3, *}$ \\ Chung-Jen Lee ${ }^{4}$ \\ Bang-Gee Hsu ${ }^{3,5}$
}

'Department of Pediatrics; ${ }^{2}$ Division of Cardiology, Buddhist

Tzu Chi General Hospital, Hualien,

Taiwan; ${ }^{3}$ School of Medicine, Tzu

Chi University, Hualien, Taiwan;

${ }^{4}$ Department of Nursing, Tzu Chi

University of Science and Technology,

Hualien, Taiwan; ${ }^{5}$ Division of

Nephrology, Buddhist Tzu Chi General

Hospital, Hualien, Taiwan

*These authors contributed equally to this work
Correspondence: Bang-Gee Hsu Division of Nephrology, Buddhist Tzu Chi General Hospital, No 707, Section 3, Chung-Yang Road, Hualien, Taiwan

Tel +8863856 I825

Fax +8863857 7161

Email gee.lily@msa.hinet.net
Purpose: Hyperleptinemia has been independently associated with human cardiovascular (CV) diseases. Accordingly, we evaluate the association between serum leptin and future CV events in patients with coronary artery disease (CAD).

Patients and methods: This study enrolled 98 patients with CAD from January to December 2012. The primary endpoint included incidences of major adverse CV events and hospitalization. Patients follow-up had been completed on June 30, 2017.

Results: After a median follow-up of 52 months, $43 \mathrm{CV}$ events had occurred. Patients with CV events had higher systolic blood pressure $(P=0.030)$, total cholesterol $(P=0.034)$, C-reactive protein $(P=0.018)$, and serum leptin levels $(P=0.001)$ than those without CV events. KaplanMeier analysis showed greater cumulative incidences of $\mathrm{CV}$ events in the high leptin group (median leptin concentration $>6.03 \mathrm{ng} / \mathrm{mL}$ ) than in the low leptin group (log-rank $P=0.012$ ). Multivariate Cox regression analysis showed that triglyceride (HR: 1.010; 95\% CI: 1.001-1.018; $P=0.022$ ) and leptin levels (HR: 1.054; 95\% CI: 1.026-1.082; $P<0.001$ ) were independently associated with $\mathrm{CV}$ events in patients with CAD.

Conclusion: Serum leptin levels could serve as a biomarker for future CV events in patients with CAD.

Keywords: leptin, coronary artery disease, cardiovascular events, triglyceride

\section{Introduction}

Coronary artery disease (CAD), one of the leading causes of death and disability worldwide, has been a significant health problem and global burden. ${ }^{1}$ According to data from the United States, an estimated 15.4 million Americans over the age of 20 had developed CAD from 2007 to 2010, with the reported prevalence increasing with age for both genders. ${ }^{1}$ Another study also reported an estimated 17.5 million deaths in 2005 due to CAD alone, a number that is expected to increase by $137 \%$ in males and $120 \%$ in females by 2020 in developing countries. ${ }^{2}$ Patients with CAD usually remain asymptomatic until their first clinically significant manifestation of pathogenic conditions, such as myocardial infarction (MI), cardiac arrest, stroke, or death from cardiovascular $(\mathrm{CV})$ events.

Leptin, a $16-\mathrm{kDa}$ obese gene product primarily secreted by white adipocytes, is the most prominent appetite- and energy-regulating peptide discovered in the early 1990s. ${ }^{3}$ Hyperleptinemia has been implicated in inflammatory, metabolic, and homeostatic factors involved in obesity, hypertension, and cardiovascular disease (CVD) ${ }^{4,5}$ Studies have revealed that leptin and its receptor's isoforms are expressed in cardiomyocytes, vascular smooth muscle cells, and endothelia. ${ }^{6-9}$ Moreover, leptin resistance with 
hyperleptinemia has been involved in enhancing endothelial oxidative stress, stimulating the proliferation of vascular smooth muscle cells, inducing neointimal and medial thickening of injured arterial vascular walls, stimulating the formation of reactive oxygen species, and activating the renin-angiotensin-aldosterone system, which together result in the imbalance between vasoconstriction and vasodilatation with the consequent development of CVD. ${ }^{5,9}$

Although the link between adipokines and CAD has been well documented, the association between serum leptin and long-term $\mathrm{CV}$ outcomes in patients with CAD has been rarely reported. ${ }^{4,10}$ Moreover, conflicting data are available concerning the association of leptin with future development of CVD. ${ }^{11-13}$ In LIPID study, plasma leptin was a significant and independent predictor of recurrent CVD in men with earlier acute coronary syndromes. ${ }^{11}$ Another study also noted high plasma leptin levels predict the congestive heart failure or cardiac death and acute coronary syndrome or stroke in patients with CAD that were followed up for two years. ${ }^{12}$ However, serum leptin level is not associated with risk of CVD but is associated with risk of diabetes in elderly. ${ }^{13}$ Therefore, the current study aims to determine the relationship between serum leptin levels and cardiometabolic risk factors among patients with CAD.

\section{Patients and methods}

\section{Patients}

Patients with $>50 \%$ stenosis in any segment after coronary angiography were identified as having CAD. After reviewing the patients' medical records between January and December 2012, 112 participants with CAD in a medical center in Hualien, eastern Taiwan were enrolled; 14 participants were excluded because of acute infection $(n=3)$, malignancy $(n=3)$, coronary bypass graft surgery $(n=2)$, and refusal to provide informed consent $(n=6)$. Finally, a total of 98 participants with CAD had been enrolled in this cross-sectional study. Using standard mercury sphygmomanometers with appropriate cuff sizes, morning BP levels of all participants who had rested for at least 10 minutes were measured on the right arm by trained staff. Systolic blood pressure (SBP) and Diastolic blood pressure (DBP) were measured three times at 5-minute intervals and were averaged for analysis. Hypertension was defined as $\mathrm{SBP} \geq 140 \mathrm{mmHg}$ and/or DBP $\geq 90 \mathrm{mmHg}$ or having received any anti-hypertensive drugs in the past two weeks according to the Eighth Joint National Committee guideline. Patients having fasting plasma glucose levels $\geq 126 \mathrm{mg} / \mathrm{dL}$ or those using oral hypoglycemic medications or insulin were diagnosed with diabetes mellitus (DM). ${ }^{14}$ This study had been approved by the
Protection of the Human Subjects Institutional Review Board of Tzu Chi University and Hospital. All participants gave written informed consent prior to study participation.

\section{Anthropometric analysis}

Body weight and height were measured to the nearest $0.5 \mathrm{~kg}$ and $0.5 \mathrm{~cm}$, respectively, with participants in light clothing without shoes. Body mass index was calculated using Quetelet's formula: weight in kilograms divided by the height in meters squared. ${ }^{5,15-17}$

\section{Biochemical investigations}

After an eight-hour overnight fast, blood samples (approximately $5 \mathrm{~mL}$ ) collected from all participants were immediately centrifuged at 3,000 $\mathrm{g}$ for 10 minutes. Serum levels of blood urea nitrogen, creatinine, fasting glucose, total cholesterol (TCH), triglycerides (TG), high-density lipoprotein cholesterol (HDL-C), low-density lipoprotein cholesterol (LDL-C), and C-reactive protein (CRP) were determined using an autoanalyzer (COBAS Integra 800; Hoffmann-La Roche Ltd., Basel, Switzerland). ${ }^{5,15-17}$ Serum leptin concentrations were determined using a commercially available enzyme immunoassay (SPI Bio Inc., Sherbrooke, QC, Canada). ${ }^{5,15}$ The estimated glomerular filtration rate was calculated using the Chronic Kidney Disease Epidemiology Collaboration equation. ${ }^{16,17}$

\section{$\mathrm{CV}$ event monitoring}

The primary endpoint was the incidence of major adverse cardiovascular events (MACEs), including death from $\mathrm{CV}$ causes, cardiac arrest, MI, stroke, nonfatal stroke or other arterial thrombotic events, and hospitalization due to $\mathrm{CV}$ conditions such as unstable or progressive angina and heart failure. The follow-up time interval (months) had not been estimated until the last hospital outpatient or inpatient record had been reviewed or the last telephone interview had been conducted (June 30, 2017). Moreover, the event time (months) had not been counted until the first MACE had occurred. Patient follow-up had been performed by a study nurse who was unaware of the participants' baseline measurements and the study protocol.

\section{Statistical analysis}

All statistical analyses were performed using the Statistical Package for the Social Sciences (SPSS) version 19.0 (IBM Corporation, Armonk, NY, USA). The distribution pattern of the variables was determined using the KolmogorovSmirnov test. Normally distributed variables were expressed 
as mean \pm standard deviation and with differences between patients being compared using the Student's independent $t$-test (two-tailed). Data not normally distributed were expressed as medians and interquartile ranges with differences between patients being compared using the MannWhitney $U$ test (TG, fasting glucose, creatinine, CRP, and leptin). Data regarding the number of patients were analyzed using the chi-squared test. Kaplan-Meier survival curves with a log-rank test were used to estimate event-free survival during follow-up based on median leptin concentrations. Univariate and multivariate Cox regression models were used to examine factors associated with $\mathrm{CV}$ events. All covariates were included in the multivariate Cox regression model. A $P$-value $<0.05$ was considered statistically significant.

\section{Results}

Demographic, clinical, and biochemical characteristics of the 98 patients with CAD are shown in Table 1. A total of $47(48.0 \%)$ and 76 (77.6\%) patients had DM and hypertension, respectively. The high leptin group (median leptin concentration $>6.03 \mathrm{ng} / \mathrm{mL})$ was older $(P=0.024)$, had higher serum levels of CRP $(P=0.015)$ and leptin $(P<0.001)$, and was shorter in height $(P=0.027)$ than the low leptin group (median leptin concentration $\leq 6.03 \mathrm{ng} / \mathrm{mL}$ ). Drugs used by the patients included angiotensin-converting enzyme inhibitors (ACEi; $\mathrm{n}=29 ; 29.6 \%$ ), angiotensin receptor blockers (ARB; $n=37 ; 37.8 \%), \beta$-blockers ( $n=58 ; 59.2 \%$ ), calcium channel blockers (CCB; $n=33 ; 33.7 \%$ ), statins ( $\mathrm{n}=71 ; 72.4 \%)$, and fibrate $(\mathrm{n}=14 ; 14.3 \%)$. No statistically significant difference in sex, comorbidity with DM or hypertension, and use of ACEi, ARB, $\beta$-blockers, CCB, statins, or fibrate had been found between the two leptin groups.

After a median follow-up of 52 months, $43 \mathrm{CV}$ events had occurred. Patients with $\mathrm{CV}$ events had higher SBP $(P=0.030)$, serum TCH $(P=0.034)$, CRP $(P=0.018)$, and leptin $(P=0.001)$ levels than those without $\mathrm{CV}$ events. No statistically significant differences in sex, comorbidity with DM or hypertension, and use of ACEi, ARB, $\beta$-blockers, $\mathrm{CCB}$, statins, or fibrate had been observed between those with and without $\mathrm{CV}$ events (Table 2).

Table I Clinical variables of the 98 coronary artery disease patients according to serum leptin levels

\begin{tabular}{|c|c|c|c|c|}
\hline Variables & $\begin{array}{l}\text { All participants } \\
(n=98)\end{array}$ & $\begin{array}{l}\text { Low leptin group } \\
(n=49)\end{array}$ & $\begin{array}{l}\text { High leptin group } \\
(n=49)\end{array}$ & $P$-value \\
\hline Age (years) & $65.65 \pm 8.71$ & $63.67 \pm 8.39$ & $67.63 \pm 8.66$ & $0.024^{a}$ \\
\hline Height (cm) & $161.84 \pm 7.54$ & $163.5 \mid \pm 7.27$ & $160.16 \pm 7.50$ & $0.027^{a}$ \\
\hline Body weight (kg) & $67.77 \pm 11.05$ & $67.96 \pm 10.58$ & $67.58 \pm 11.60$ & 0.867 \\
\hline Body mass index $\left(\mathrm{kg} / \mathrm{m}^{2}\right)$ & $25.78 \pm 3.11$ & $25.28 \pm 2.51$ & $26.28 \pm 3.58$ & 0.115 \\
\hline SBP (mmHg) & $131.90 \pm 18.10$ & $130.65 \pm 17.46$ & $133.14 \pm 18.81$ & 0.499 \\
\hline $\mathrm{DBP}(\mathrm{mmHg})$ & $71.94 \pm 9.46$ & $71.16 \pm 10.05$ & $72.71 \pm 8.87$ & 0.420 \\
\hline Total cholesterol (mg/dL) & $164.95 \pm 33.03$ & $164.98 \pm 35.37$ & $164.92 \pm 30.88$ & 0.993 \\
\hline Triglycerides (mg/dL) & I I 6.00 (89.75-I65.00) & $109.00(88.50-152.00)$ & $121.00(9|.50-| 74.00)$ & 0.670 \\
\hline HDL-C (mg/dL) & $44.98 \pm 12.46$ & $44.86 \pm 11.55$ & $45.10 \pm 13.43$ & 0.923 \\
\hline LDL-C (mg/dL) & $96.36 \pm 25.90$ & $97.86 \pm 27.06$ & $94.86 \pm 24.87$ & 0.569 \\
\hline Fasting glucose (mg/dL) & $107.50(95.00-134.00)$ & $105.00(98.50-130.00)$ & $108.00(93.50-164.00)$ & 0.898 \\
\hline Blood urea nitrogen (mg/dL) & $16.70 \pm 5.56$ & $17.12 \pm 5.43$ & $|6.29 \pm 5.7|$ & 0.459 \\
\hline Creatinine (mg/dL) & $\mathrm{I} .10(0.90-\mathrm{I} .30)$ & I.IO (0.90-I.30) & $\mathrm{I} .00(0.90-\mathrm{I} .25)$ & 0.317 \\
\hline Glomerular filtration rate $(\mathrm{mL} / \mathrm{min})$ & $68.87 \pm 19.09$ & $68.71 \pm 19.77$ & $69.02 \pm 18.59$ & 0.936 \\
\hline Leptin (ng/mL) & $6.03(3.37-13.69)$ & $3.40(1.82-4.31)$ & $13.60(8.46-28.81)$ & $<0.00 I^{a}$ \\
\hline C-reactive protein (mg/dL) & $0.20(0.14-0.26)$ & $0.18(0.14-0.23)$ & $0.21(0.16-0.37)$ & $0.015^{\mathrm{a}}$ \\
\hline Female (\%) & $21(2 \mathrm{l} .4)$ & $7(14.3)$ & $14(28.6)$ & 0.085 \\
\hline Diabetes (\%) & $47(48.0)$ & $25(51.0)$ & $22(44.9)$ & 0.544 \\
\hline Hypertension (\%) & $76(77.6)$ & $37(75.5)$ & $39(79.6)$ & 0.628 \\
\hline ACE inhibitor use & $29(29.6)$ & $16(32.7)$ & $13(26.5)$ & 0.507 \\
\hline ARB use & $37(37.8)$ & $16(32.7)$ & $21(42.9)$ & 0.297 \\
\hline$\beta$-blocker use & $58(59.2)$ & $28(57.1)$ & $30(6 \mid .2)$ & 0.681 \\
\hline CCB use & $33(33.7)$ & $14(28.6)$ & $19(38.8)$ & 0.285 \\
\hline Statin use & 7I (72.4) & $34(69.4)$ & $37(75.5)$ & 0.498 \\
\hline Fibrate use & $14(14.3)$ & $4(8.2)$ & $10(20.4)$ & 0.083 \\
\hline
\end{tabular}

Notes: Values for continuous variables given as mean \pm SD and compared by Student's $t$-test; variables not normally distributed given as medians and interquartile range and compared by Mann-Whitney $U$ test; values are presented as number (\%), and analysis was performed using the chi-squared test. a $<0.05$.

Abbreviations: ACE, angiotensin-converting enzyme; ARB, angiotensin-receptor blocker; CCB, calcium-channel blocker; DBP, diastolic blood pressure; HDL-C, highdensity lipoprotein cholesterol; LDL-C, low-density lipoprotein cholesterol; SBP, systolic blood pressure. 
Table 2 Clinical variables of the 98 coronary artery disease patients with or without cardiovascular event

\begin{tabular}{|c|c|c|c|}
\hline Variables & $\begin{array}{l}\text { Participants without } \\
\text { cardiovascular events }(n=55)\end{array}$ & $\begin{array}{l}\text { Participants with } \\
\text { cardiovascular events }(n=43)\end{array}$ & $P$-value \\
\hline Age (years) & $66.00 \pm 8.60$ & $65.21 \pm 8.94$ & 0.658 \\
\hline Height $(\mathrm{cm})$ & $162.13 \pm 7.67$ & $161.47 \pm 7.45$ & 0.668 \\
\hline Body weight $(\mathrm{kg})$ & $67.40 \pm 11.16$ & $68.25 \pm 11.02$ & 0.709 \\
\hline Body mass index $\left(\mathrm{kg} / \mathrm{m}^{2}\right)$ & $25.56 \pm 3.27$ & $26.07 \pm 2.91$ & 0.425 \\
\hline $\mathrm{SBP}(\mathrm{mmHg})$ & $128.40 \pm 15.49$ & $136.37 \pm 20.28$ & $0.030^{\mathrm{a}}$ \\
\hline $\mathrm{DBP}(\mathrm{mmHg})$ & $70.98 \pm 10.13$ & $73.16 \pm 8.49$ & 0.260 \\
\hline Total cholesterol (mg/dL) & $|58.7| \pm 27.8 \mid$ & $172.93 \pm 37.53$ & $0.034^{\mathrm{a}}$ \\
\hline Triglycerides (mg/dL) & $108.00(89.00-151.00)$ & $129.00(91.00-195.00)$ & 0.184 \\
\hline $\mathrm{HDL}-\mathrm{C}(\mathrm{mg} / \mathrm{dL})$ & $44.27 \pm 11.19$ & $45.88 \pm 14.01$ & 0.528 \\
\hline LDL-C (mg/dL) & $93.05 \pm 23.94$ & $100.58 \pm 27.92$ & 0.154 \\
\hline Fasting glucose (mg/dL) & $106.00(95.00-132.00)$ & $108.00(95.00-157.00)$ & 0.564 \\
\hline Blood urea nitrogen (mg/dL) & $16.75 \pm 5.68$ & $16.65 \pm 5.47$ & 0.934 \\
\hline Creatinine $(\mathrm{mg} / \mathrm{dL})$ & $1.10(0.90-1.30)$ & $1.00(0.90-1.40)$ & 0.746 \\
\hline Glomerular filtration rate $(\mathrm{mL} / \mathrm{min})$ & $68.29 \pm 17.44$ & $69.61 \pm 21.20$ & 0.736 \\
\hline Leptin $(\mathrm{ng} / \mathrm{mL})$ & $4.59(2.79-8.5 \mathrm{I})$ & $9.91(4.32-34.49)$ & $0.00 I^{\mathrm{a}}$ \\
\hline C-reactive protein (mg/dL) & $0.18(0.14-0.24)$ & $0.21(0.17-0.37)$ & $0.018^{\mathrm{a}}$ \\
\hline Female (\%) & II (20.0) & $10(23.3)$ & 0.697 \\
\hline Diabetes (\%) & $24(43.6)$ & $23(53.5)$ & 0.333 \\
\hline Hypertension (\%) & 39 (70.9) & $37(88.6)$ & 0.075 \\
\hline$A C E$ inhibitor use & $19(34.5)$ & $10(23.3)$ & 0.224 \\
\hline ARB use & $17(30.9)$ & $20(46.5)$ & 0.114 \\
\hline$\beta$-blocker use & $32(58.2)$ & $26(60.5)$ & 0.819 \\
\hline $\mathrm{CCB}$ use & $15(27.3)$ & $18(41.9)$ & 0.129 \\
\hline Statin use & $42(76.4)$ & $29(67.4)$ & 0.327 \\
\hline Fibrate use & $6(9.1)$ & $9(20.9)$ & 0.096 \\
\hline
\end{tabular}

Notes: Values for continuous variables given as mean \pm SD and compared by Student's $t$-test; variables not normally distributed given as medians and interquartile range and compared by Mann-Whitney $U$ test; values are presented as number (\%), and analysis was performed using the chi-squared test. ap $<0.05$ was considered statistically significant. Abbreviations: ACE, angiotensin-converting enzyme; ARB, angiotensin-receptor blocker; CCB, calcium-channel blocker; DBP, diastolic blood pressure; HDL-C, highdensity lipoprotein cholesterol; LDL-C, low-density lipoprotein cholesterol; SBP, systolic blood pressure.

Kaplan-Meier analysis showed that the cumulative incidence of $\mathrm{CV}$ events was greater in the high leptin group (median leptin concentration $>6.03 \mathrm{ng} / \mathrm{mL}$ ) than in the low leptin group (log-rank $P=0.012$ ) (Figure 1). Univariate Cox regression analysis revealed that SBP (HR: $1.018 ; 95 \% \mathrm{CI}$ : 1.003-1.034; $P=0.021$ ), TCH (HR: 1.010 ; $95 \%$ CI: $1.001-$ $1.020 ; P=0.035)$, TG (HR: $1.004 ; 95 \%$ CI: $1.001-1.006$; $P=0.006$ ), CRP (HR: 4.329; 95\% CI: 2.027-9.246; $P<0.001$ ),

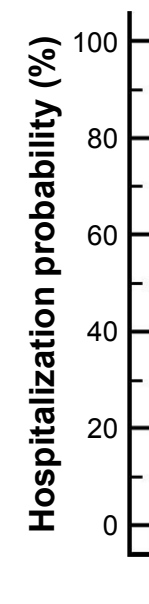

Leptin $\leq 6.03 \mathrm{ng} / \mathrm{mL} \quad 49$
Leptin $>6.03 \mathrm{ng} / \mathrm{mL} \quad 49$
Number at risk

$\begin{array}{ll}44 & 42 \\ 43 & 39\end{array}$

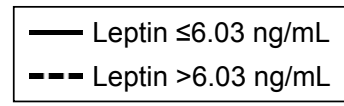

Figure I Kaplan-Meier analysis of cardiovascular events in 98 patients with coronary artery disease according to median serum leptin levels. 
Table 3 Cox regression of univariate and multivariate significant predictors of cardiovascular events among the 98 patients with coronary artery disease

\begin{tabular}{|c|c|c|c|c|}
\hline & \multicolumn{2}{|l|}{ Univariate } & \multicolumn{2}{|l|}{ Multivariate } \\
\hline & Hazard ratio $(95 \% \mathrm{Cl})$ & $P$-value & Hazard ratio $(95 \% \mathrm{Cl})$ & P-value \\
\hline Age (years) & $0.995(0.96 \mathrm{I}-1.030)$ & 0.779 & - & - \\
\hline Height (cm) & $0.995(0.957-1.035)$ & 0.801 & - & - \\
\hline Body weight (kg) & $1.006(0.979-1.034)$ & 0.679 & - & - \\
\hline Body mass index $\left(\mathrm{kg} / \mathrm{m}^{2}\right)$ & I.035 (0.94I-I.I39) & 0.475 & - & - \\
\hline $\mathrm{SBP}(\mathrm{mmHg})$ & $1.018(1.003-1.034)$ & $0.021^{\mathrm{a}}$ & - & - \\
\hline $\mathrm{DBP}(\mathrm{mmHg})$ & $1.020(0.988-1.053)$ & 0.222 & - & - \\
\hline Total cholesterol (mg/dL) & $1.010(1.001-1.020)$ & $0.035^{\mathrm{a}}$ & - & - \\
\hline Triglycerides (mg/dL) & $1.004(1.00 \mathrm{I}-1.006)$ & $0.006^{a}$ & $1.010(1.001-1.018)$ & $0.022^{\mathrm{a}}$ \\
\hline $\mathrm{HDL}-\mathrm{C}(\mathrm{mg} / \mathrm{dL})$ & $1.007(0.983-1.032)$ & 0.563 & - & - \\
\hline LDL-C (mg/dL) & $1.008(0.996-1.021)$ & 0.180 & - & - \\
\hline Fasting glucose (mg/dL) & $1.002(0.996-1.007)$ & 0.527 & - & - \\
\hline Blood urea nitrogen (mg/dL) & $1.006(0.955-1.060)$ & 0.825 & - & - \\
\hline Creatinine $(\mathrm{mg} / \mathrm{dL})$ & I. I 38 (0.457-2.832) & 0.781 & - & - \\
\hline Glomerular filtration rate $(\mathrm{mL} / \mathrm{min})$ & $1.002(0.985-1.019)$ & 0.822 & - & - \\
\hline Leptin $(\mathrm{ng} / \mathrm{mL})$ & $1.043(1.025-1.062)$ & $<0.00 \mathrm{I}^{\mathrm{a}}$ & $1.054(1.026-1.082)$ & $<0.001^{2}$ \\
\hline C-reactive protein (mg/dL) & $4.329(2.027-9.246)$ & $<0.00 \mathrm{I}^{\mathrm{a}}$ & - & - \\
\hline Female (\%) & $1.138(0.560-2.31 \mathrm{I})$ & 0.721 & - & - \\
\hline Diabetes (\%) & $1.336(0.733-2.434)$ & 0.345 & - & - \\
\hline Hypertension (\%) & $2.052(0.865-4.868)$ & 0.103 & - & - \\
\hline
\end{tabular}

Note: a $<0.05$ was considered statistically significant.

Abbreviations: DBP, diastolic blood pressure; HDL-C, high-density lipoprotein cholesterol; LDL-C, low-density lipoprotein cholesterol; SBP, systolic blood pressure.

and leptin (HR: 1.043; 95\% CI: 1.025-1.062; $P<0.001$ ) levels were positively associated with $\mathrm{CV}$ events in patients with CAD. Furthermore, multivariate Cox regression analysis showed that TG (HR: 1.010 ; 95\% CI: 1.001-1.018; $P=0.022$ ) and leptin (HR: 1.054; 95\% CI: 1.026-1.082; $P<0.001)$ levels were independently associated with $\mathrm{CV}$ events in patients with CAD (Table 3).

\section{Discussion}

The results presented herein revealed that patients with CAD who developed MACEs during follow-up had higher fasting leptin levels than those who did not. Moreover, fasting serum leptin and TG levels were independently associated with increased risk for MACEs among patients with CAD.

Aging is usually associated with hyperleptinemia and leptin resistance, which may aggravate age-associated pathologies, including metabolic syndrome and CVD. ${ }^{18,19}$ The present study also revealed that patients in the high leptin group were older than those in low leptin group. Hypertension has been a major independent risk factor for $\mathrm{CAD}$ across all age, gender, and race groups. ${ }^{20} \mathrm{~A}$ previous large-scale meta-analysis involving approximately 1 million adults had revealed that BP was correlated with fatal CAD across all ages and that an overall SBP increase of $20 \mathrm{mmHg}$ doubles the risk for fatal coronary events. ${ }^{21}$ A recent systematic review and meta-analysis had also confirmed that intensive BP reductions had additional benefits on major CV events and all-cause mortality. ${ }^{22}$ Accordingly, the present study also revealed that patients with CAD who developed a new MACE had significantly higher SBP than those who did not, suggesting that BP reduction is important for preventing further MACE development in patients with CVD. Several previous studies have suggested that inflammation and dyslipidemia may play important roles in not only the occurrence and progression of coronary atherosclerotic lesions but also treatment outcome after intervention. ${ }^{23-25}$ The present study also observed significantly higher CRP values in the high serum leptin group than in low leptin group. Moreover, significantly higher TCH and CRP levels were found in those who developed a new MACE than in those who did not, which is consistent with a previous study by Xu et al. ${ }^{25}$

In contrast with traditional risk factors for $\mathrm{CAD}$, growing evidence has revealed that leptin resistance with hyperleptinemia, a phenomenon encountered in obesity and insulin resistance, plays an important role in the occurrence, severity, and extent of CV events. ${ }^{10,15,26,27}$ Although the definitive role of leptin in the development of CVD remains to be clarified. One study noted lower serum leptin level that measured 7 days after acute MI onset is associated with a high incidence of adverse events in Japanese patients. ${ }^{28}$ Another study noted low serum leptin level is independent predictors of high risk coronary anatomy as defined by an integrated coronary computed tomography angiography risk score in 
patients with stable chest pain. ${ }^{29}$ Our previous study and several other reports had found that high circulating leptin levels were positively correlated with the number of stenotic coronary arteries. ${ }^{15,26}$ Hyperleptinemia was associated with heart failure and impaired diastolic function in patients with CAD. ${ }^{30}$ In addition, leptin exhibited profibrotic effects on the myocardium, which could induce myocardial fibrosis and aggravate the severity of heart disease. ${ }^{31}$ Leptin is also an independent predictor of $\mathrm{CV}$ event recurrence in males with earlier acute coronary syndromes, while hyperleptinemia has been positively associated with restenosis rate after percutaneous coronary intervention. ${ }^{11}$ Moreover, after both univariate and multivariate Cox regression analyses, a very recent study revealed that circulating leptin levels could significantly predict the occurrence of not only MACEs, such as short-term congestive heart failure events, cardiac deaths, or acute coronary syndromes, but also strokes. ${ }^{12}$ Our present findings also revealed that patients with CAD who developed a new MACE had significantly higher serum leptin levels than those who did not. Taken together, whether the complex interaction of leptin with metabolic and CV system could account for a "CAD progression" effect needs further study.

The present study showed that hyperleptinemia and hypertriglyceridemia independently and significantly increased the risk of MACE in patients with CAD after univariate and multivariate Cox regression analyses. The mechanism by which leptin induces adverse CV events among patients with CAD is likely to be multifactorial. Leptin had also been identified as an adipokine that could potentially be involved in crosstalk between adipose tissues and the vascular wall. ${ }^{7,831}$ Hyperleptinemia had been associated with intima-media thickness of the common carotid artery, smooth muscle cell migration and proliferation, and coronary artery calcification, all of which were markers of asymptomatic atherosclerosis and important pathological vascular changes in patients with hypertension and CAD. ${ }^{7,31-33}$ The direct influence of hypertension on future $\mathrm{CV}$ events has been well documented. A previous study also reported that hyperleptinemia was positively associated with hypertension. ${ }^{34}$ Based on findings from Cox regression analyses, the present study confirmed that elevated SBP increased the risk of MACEs among patients with $\mathrm{CAD}$, suggesting that hyperleptinemia may aggravate hypertension-induced MACEs.

CRP, a well-established biomarker of inflammation, has been positively associated with CAD presence and progression. ${ }^{24}$ Previous studies had revealed that high leptin and CRP levels increase the risk for CV death in Western countries and Taiwan. ${ }^{35,36}$ Leptin has been associated with a pro-inflammatory, atherogenic milieu, while several studies had reported that serum leptin levels were positively correlated with hs-CRP levels. ${ }^{37,38}$ Our previous study also revealed that elevated CRP levels were independent predictors of hyperleptinemia among patients with hypertension. ${ }^{5}$ Accordingly, the current study revealed that among patients with CAD, those who developed a new MACE had significantly higher CRP levels than those who did not. Associations between leptin and pro-atherogenic blood lipids, along with leptin's pro-inflammatory activity and role in insulin resistance and endothelial dysfunction, comprise the major mechanisms for triggering atherosclerosis and further aggravating CVD. ${ }^{10}$

\section{Limitations}

Some limitations to the present study are worth mentioning. First, the limited number of patients with MACE, uneven distribution of sex, not included obesity subjects, obtained from a single center, as well as the lack of evaluation regarding some lifestyle habits that could influence the occurrence of MACE, such as smoking or alcohol drinking, may restrict the predictive power of the current study. Second, although several of the medications used by our study population may influence their atherosclerotic and inflammatory status, the present study showed that ACEi, ARB, $\beta$-blockers, $\mathrm{CCB}$, statins, and fibrates had no influence on circulating leptin levels or new MACE development. Many independent studies have reported that the pleiotropic effects of statins included modulation of serum leptin levels, while treatment with atorvastatin lowered circulating leptin levels in patients with CAD. ${ }^{39,40}$ A previous study also revealed that lipid profiles, including TG, TCH, LDL-C, and HDL-C, have poor predictive values for the severity of coronary diseases due to the influence of drug therapy. ${ }^{41}$ Further studies are needed to evaluate the impact of the aforementioned medication on serum leptin concentrations and new MACE development among patients with CAD.

\section{Conclusion}

In addition to the traditional risk factors for CAD, hyperleptinemia may serve as a novel, independent risk factor for $\mathrm{CV}$ events among patients with CAD and may increase the predictive power for MACEs. Moreover, while a previous study revealed that circulating leptin levels could serve as an additional tool for short-term risk stratification of patients with $\mathrm{CAD},{ }^{26}$ our results showed that such a finding could be further extended to include long-term $\mathrm{CV}$ events among 
patients with CAD. Further studies are needed to evaluate the direct cause-and-effect association between serum leptin and CAD can be established.

\section{Acknowledgments}

This study was supported by a grant from the Buddhist Tzu Chi General Hospital, Hualien, Taiwan (TCRD101-03). MC Chen, JH Wang, and BG Hsu conceived and designed the experiments. CJ Lee and JH Wang performed the experiments. CJ Lee and BG Hsu analyzed the data. MC Chen and BG Hsu wrote the manuscript. All authors reviewed and approved the final version of this paper.

\section{Disclosure}

The authors report no conflicts of interest in this work.

\section{References}

1. Go AS, Mozaffarian D, Roger VL, et al. Heart disease and stroke statistics - 2014 update: a report from the American Heart Association. Circulation. 2014;129(3):e28-e292.

2. Jayashree S, Arindam M, Vijay KV. Genetic epidemiology of coronary artery disease: an Asian Indian perspective. J Genet. 2015;94(3): 539-549.

3. Ghalandari H, Hosseini-Esfahani F, Mirmiran P. The association of polymorphisms in leptin/leptin receptor genes and ghrelin/ghrelin receptor genes with overweight/obesity and the related metabolic disturbances: a review. Int J Endocrinol Metab. 2015;13(3):e19073.

4. Wannamethee SG, Tchernova J, Whincup P, et al. Plasma leptin: associations with metabolic, inflammatory and haemostatic risk factors for cardiovascular disease. Atherosclerosis. 2007;191(2):418-426.

5. Chen MC, Hsu BG, Lee CJ, et al. Hyperleptinemia positively correlates with cardiometabolic syndrome in hypertensive patients. Int J Clin Exp Pathol. 2016;9:12959-12967.

6. Rajapurohitam V, Gan XT, Kirshenbaum LA, Karmazyn M. The obesity-associated peptide leptin induces hypertrophy in neonatal rat ventricular myocytes. Circ Res. 2003;93(4):277-279.

7. Oda A, Taniguchi T, Yokoyama M. Leptin stimulates rat aortic smooth muscle cell proliferation and migration. Kobe J Med Sci. 2001; 47(3):141-150.

8. Heida NM, Leifheit-Nestler M, Schroeter MR, et al. Leptin enhances the potency of circulating angiogenic cells via src kinase and integrin (alpha)vbeta5: implications for angiogenesis in human obesity. Arterioscler Thromb Vasc Biol. 2010;30(2):200-206.

9. Bouloumie A, Marumo T, Lafontan M, Busse R. Leptin induces oxidative stress in human endothelial cells. Faseb J. 1999;13(10):1231-1238.

10. Li ZY, Wang P, Miao CY. Adipokines in inflammation, insulin resistance and cardiovascular disease. Clin Exp Pharmacol Physiol. 2011;38(12):888-896.

11. Söderberg S, Colquhoun D, Keech A, et al. Leptin, but not adiponectin, is a predictor of recurrent cardiovascular events in men: results from the LIPID study. Int J Obes. 2009;33(1):123-130.

12. Puurunen VP, Kiviniemi A, Lepojärvi S, et al. Leptin predicts short-term major adverse cardiac events in patients with coronary artery disease. Ann Med. 2017;49(5):448-454.

13. Welsh P, Murray HM, Buckley BM, et al. Leptin predicts diabetes but not cardiovascular disease: results from a large prospective study in an elderly population. Diabetes Care. 2009;32(2):308-310.

14. Alberti KG, Zimmet PZ, Definition ZPZ. Definition, diagnosis and classification of diabetes mellitus and its complications. Part 1: diagnosis and classification of diabetes mellitus provisional report of a WHO consultation. Diabet Med. 1998;15(7):539-553.
15. Tsai JP, Wang JH, Chen ML, et al. Association of serum leptin levels with central arterial stiffness in coronary artery disease patients. $B M C$ Cardiovasc Disord. 2016;16:80.

16. Wang JH, Lee CJ, Yang CF, Chen YC, Hsu BG. Serum resistin as an independent marker of aortic stiffness in patients with coronary artery disease. PLoS One. 2017;12(8):e0183123.

17. Chen MC, Hsu BG, Lee CJ, Yang CF, Wang JH. High serum adipocyte fatty acid binding protein level as a potential biomarker of aortic arterial stiffness in hypertensive patients with metabolic syndrome. Clin Chim Acta. 2017;473:166-172.

18. Ma XH, Muzumdar R, Yang XM, et al. Aging is associated with resistance to effects of leptin on fat distribution and insulin action. J Gerontol A Biol Sci Med Sci. 2002;57(6):B225-B231.

19. Roszkowska-Gancarz M, Jonas M, Owczarz M, et al. Age-related changes of leptin and leptin receptor variants in healthy elderly and long-lived adults. Geriatr Gerontol Int. 2015;15(3):365-371.

20. Rosendorff C, Lackland DT, Allison M, et al. Treatment of hypertension in patients with coronary artery disease: a scientific statement from the American Heart Association, American College of Cardiology, and American Society of Hypertension. Circulation. 2015;131(19): e435-e470.

21. Lewington S, Clarke R, Qizilbash N, et al. Age-specific relevance of usual blood pressure to vascular mortality: a meta-analysis of individual data for one million adults in 61 prospective studies. Lancet. 2002; 360(9349):1903-1913.

22. Xie X, Atkins E, Lv J, et al. Effects of intensive blood pressure lowering on cardiovascular and renal outcomes: updated systematic review and meta-analysis. Lancet. 2016;387(10017):435-443.

23. Wilson PW. Evidence of systemic inflammation and estimation of coronary artery disease risk: a population perspective. Am J Med. 2008; 121(10 Suppl 1):S15-S20.

24. Zairis MN, Ambrose JA, Manousakis SJ, et al. The impact of plasma levels of C-reactive protein, lipoprotein (a) and homocysteine on the long-term prognosis after successful coronary stenting: The Global Evaluation of New Events and Restenosis After Stent Implantation Study. J Am Coll Cardiol. 2002;40(8):1375-1382.

25. Xu HY, Qiao SB, Zhang JF, Dong QT, Li JJ. Different impacts of C-reactive protein and lipid profile on coronary lesions following a percutaneous coronary intervention. Coron Artery Dis. 2012;23(3):181-187.

26. Khafaji HA, Bener AB, Rizk NM, Al Suwaidi J. Elevated serum leptin levels in patients with acute myocardial infarction; correlation with coronary angiographic and echocardiographic findings. BMC Res Notes. 2012;5:262.

27. Morita Y, Maeda K, Kondo T, et al. Impact of adiponectin and leptin on long-term adverse events in Japanese patients with acute myocardial infarction. Results from the Nagoya Acute Myocardial Infarction Study (NAMIS). Circ J. 2013;77(11):2778-2785.

28. Caselli C, de Graaf MA, Lorenzoni V, et al. HDL cholesterol, leptin and interleukin-6 predict high risk coronary anatomy assessed by CT angiography in patients with stable chest pain. Atherosclerosis. 2015;241(1):55-61.

29. Puurunen VP, Lepojärvi ES, Piira OP, et al. High plasma leptin levels are associated with impaired diastolic function in patients with coronary artery disease. Peptides. 2016;84:17-21.

30. Zibadi S, Cordova F, Slack EH, Watson RR, Larson DF. Leptin's regulation of obesity-induced cardiac extracellular matrix remodeling. Cardiovasc Toxicol. 2011;11(4):325-333.

31. Ciccone M, Vettor R, Pannacciulli N, et al. Plasma leptin is independently associated with the intima-media thickness of the common carotid artery. Int J Obes Relat Metab Disord. 2001;25(6):805-810.

32. Larsen BA, Laughlin GA, Cummins K, Barrett-Connor E, Wassel CL. Adipokines and severity and progression of coronary artery calcium: findings from the Rancho Bernardo Study. Atherosclerosis. 2017; 265:1-6.

33. Weissgerber A, Scholz M, Teren A, et al. The value of noncoronary atherosclerosis for identifying coronary artery disease: results of the Leipzig LIFE Heart Study. Clin Res Cardiol. 2016;105(2):172-181. 
34. Agata J, Masuda A, Takada M, et al. High plasma immunoreactive leptin level in essential hypertension. Am J Hypertens. 1997;10(10 Pt 1): 1171-1174.

35. Amrock SM, Weitzman M. Effect of increased leptin and C-reactive protein levels on mortality: results from the National Health and Nutrition Examination Survey. Atherosclerosis. 2014;236(1):1-6.

36. Chiu FH, Chuang CH, Li WC, Wc L, et al. The association of leptin and $\mathrm{C}$-reactive protein with the cardiovascular risk factors and metabolic syndrome score in Taiwanese adults. Cardiovasc Diabetol. 2012;11:40.

37. Viikari LA, Huupponen RK, Viikari JS, et al. Relationship between leptin and C-reactive protein in young Finnish adults. J Clin Endocrinol Metab. 2007;92(12):4753-4758.

38. Ntyintyane L, Panz V, Raal FJ, Gill G. Leptin, adiponectin, and highsensitivity C-reactive protein in relation to the metabolic syndrome in urban South African blacks with and without coronary artery disease. Metab Syndr Relat Disord. 2009;7(3):243-248.
39. Krysiak R, Labuzek K, Okopień B. Effect of atorvastatin and fenofibric acid on adipokine release from visceral and subcutaneous adipose tissue of patients with mixed dyslipidemia and normolipidemic subjects. Pharmacol Rep. 2009;61(6):1134-1145.

40. Sun YM, Li J, Luan Y, Wang LF. Effect of statin therapy on leptin levels in patients with coronary heart disease. Peptides. 2010;31(6): 1205-1207.

41. Gumanova NG, Gavrilova NE, Chernushevich OI, Kots AY, Metelskaya VA. Ratios of leptin to insulin and adiponectin to endothelin are sex-dependently associated with extent of coronary atherosclerosis. Biomarkers. 2017;22(3-4):239-245.

\section{Publish your work in this journal}

Therapeutics and Clinical Risk Management is an international, peerreviewed journal of clinical therapeutics and risk management, focusing on concise rapid reporting of clinical studies in all therapeutic areas, outcomes, safety, and programs for the effective, safe, and sustained use of medicines. This journal is indexed on PubMed Central, CAS,
EMBase, Scopus and the Elsevier Bibliographic databases. The manuscript management system is completely online and includes a very quick and fair peer-review system, which is all easy to use. Visit http://www.dovepress.com/testimonials.php to read real quotes from published authors. 